\title{
Case Report: Autochthonous Case of Human Visceral Leishmaniasis in the West Bank, Palestine
}

\author{
Ahmed Al-Jawabreh, ${ }^{1,2}$ Suheir Ereqat, ${ }^{2}$ Kamal Dumaidi, ${ }^{3}$ Abdelmajeed Nasereddin, ${ }^{4}$ Samer Sawalha, ${ }^{5}$ Hanan Al-Jawabreh, ${ }^{1}$ and \\ Amer Al-Jawabreh ${ }^{1,3 *}$ \\ ${ }^{1}$ Leishmaniases Research Unit, Jericho, Palestine; ${ }^{2}$ Faculty of Medicine, Al-Quds University, Jerusalem, Palestine; ${ }^{3}$ Arab American University, \\ Jenin, Palestine; ${ }^{4}$ Al-Quds Nutrition and Health Research Institute, Faculty of Medicine, Al-Quds University Abu Deis, Jerusalem, Palestine; \\ ${ }^{5}$ Ministry of Health, Ramallah, Palestine
}

\begin{abstract}
Human visceral leishmaniasis (HVL) is a parasitic disease infecting children in the Mediterranean region. Here, we portray a case of a 2-year-old child with an epidemiological description of the situation surrounding the case. The patient was suffering from recurrent fever, weakness, and abdominal discomfort associated with loss of appetite. Routine blood investigations showed pancytopenia, whereas examination revealed hepatomegaly. A diagnosis of HVL was made by demonstrating amastigotes in a Giemsa-stained smear from a bone marrow aspirate followed by genotyping by PCR and sequencing. In conclusion, early detection of VL infection followed by appropriate treatment protocols is essential to saving the patient.
\end{abstract}

\section{INTRODUCTION}

Visceral leishmaniasis (VL) in the Mediterranean Basin is a zoonotic disease caused by the protozoan parasite Leishmania infantum which, if not treated, is fatal to humans and canids. Visceral leishmaniasis caused by $L$. infantum is transmitted by the bite of 20 female sandfly species, seven of which have been reported in the northern and southern Mediterranean regions including Phlebotomus papatasi, Phlebotomus (larroussius) perniciosus, Phlebotomus (larroussius) syriacus, Phlebotomus (larroussius) ariasi, Phlebotomus (larroussius) neglectus, Phlebotomus (larroussius) tobbi, and Phlebotomus (larroussius) perfiliewi. ${ }^{1-6}$ Dog is the main reservoir and host showing symptoms ranging from mildly asymptomatic to apparently severe manifestations. ${ }^{7}$ Around 2.5 million dogs are estimated to be infected with L. infantum in the Mediterranean region. ${ }^{8}$ A study in Palestine showed that $17 \%$ of the domestic dogs suffered from canine $V L$ caused by $L$. infantum. ${ }^{9}$ Human visceral leishmaniasis (HVL) commonly causes prolonged high-grade fever (up to $40^{\circ} \mathrm{C}$ ), paleness, and hepatosplenomegaly. Other symptoms include anorexia, irritability, rhinorrhea, vomiting, and diarrhea. ${ }^{10}$ Laboratory findings in HVL cases include pancytopenia, neutropenia, thrombocytopenia, microcytic hypochromic anemia, elevated C-reactive protein (CRP) (>100 mg/L), and erythrocyte sedimentation rate (ESR) (> $40 \mathrm{~mm} /$ hour). ${ }^{10}$ Approximately 50,000-90,000 new cases of HVL are estimated to occur worldwide each year, out of which only an estimated $25-45 \%$ is reported. More than $95 \%$ of new cases occurred in 10 countries: Bangladesh, Brazil, China, Ethiopia, India, Kenya, Nepal, Somalia, South Sudan, and Sudan. ${ }^{11}$ In the Mediterranean region, VL is reported in 25 countries, with a total of 875 reported cases and an estimated number of cases ranging between 1,200 and 2,000 per year. In Palestine, VL is rare and only sporadically affecting children., ${ }^{9,13}$ Three of the seven potential sandfly vectors of $L$. infantum in the Mediterranean area have been caught in Palestine. ${ }^{14}$ In this study, we report a case of VL caused by $L$. infantum in a rural area in Palestine and investigate the life cycle components, vector, and reservoir, in the patient's vicinity.

*Address correspondence to Amer Al-Jawabreh, Jericho, Al-Quds st., The West Bank, Palestine. E-mails: islahj@@yahoo.com or amer. aljawabreh@aaup.edu

\section{METHODS}

Bone marrow aspirate was taken from the back of the pelvic bone (upper iliac crest) of the patient in Beit-Jala government hospital as part of the routine diagnostic procedure as described by Bain. ${ }^{15}$ Blood was collected by venipuncture of the median cubital vein in the antecubital fossa antecubital vein for blood chemistry and hematology profile according to protocol. One drop of bone marrow aspirate was spread on a slide as thin film, air-dried, fixed in absolute methanol, and Giemsastained as described by others. ${ }^{16}$ The unstained bone marrow on one of the slides was scrapped off and DNA-extracted using Qiagen kit (Qiagen, Hilden, Germany) according to the manufacturer's instructions and kept at $-20^{\circ} \mathrm{C}$ until use. PCR was used to amplify the internal transcribed spacer 1-PCR as described earlier. ${ }^{17-19}$ Amplicon was sent for commercial sequencing. The DNA sequence was used to identify species of leishmania by BLAST search against leishmania species in the GenBank (www.ncbi.nlm.nih.gov) database. Blood samples were collected from dogs in the patient's village (Beit Ola village in Al-Khalil) and its vicinity and processed as described earlier. ${ }^{9}$ Dogs' sera were tested for the presence of antileishmanial antibodies by ELISA as described elswhere. ${ }^{9}$ Sand flies were collected from the patient's house using aspirators. Collection was conducted early morning in the month of June during the biting season. Sandfly identification and classification were conducted using conventional keys. ${ }^{14}$ Leishmanial infection rate and identification of leishmania species in sand flies were conducted simultaneously by nextgeneration sequencing using Illumina MiSeq next-generation sequencer as described previously. ${ }^{20,21}$

\section{CASE PRESENTATION}

A 2-year-old female child from a mountainous rural area in Palestine was referred to the local government hospital in September 2018 after 2 months of suffering from prolonged high fever $\left(41^{\circ} \mathrm{C}\right)$ and loss of appetite. Physical examination confirmed by ultrasonography manifested hepatomegaly of $12.3 \mathrm{~cm}$ (normal is $9 \mathrm{~cm}$ ). In the laboratory, complete blood count revealed pancytopenia: hemoglobin level of 7.0 (reference range: $11.5-15.5 \mathrm{~g} / \mathrm{dL}$ ), hematocrit of 22.3 (reference range: $33-49 \%$ ), erythrocyte count of $3.27 \times 10^{6} / \mu \mathrm{L}$ (reference range: $\left.3.7-5.3 \times 10^{6} / \mu \mathrm{L}\right)$, leukocyte count of $5.0 \times 10^{3} / \mu \mathrm{L}$ 


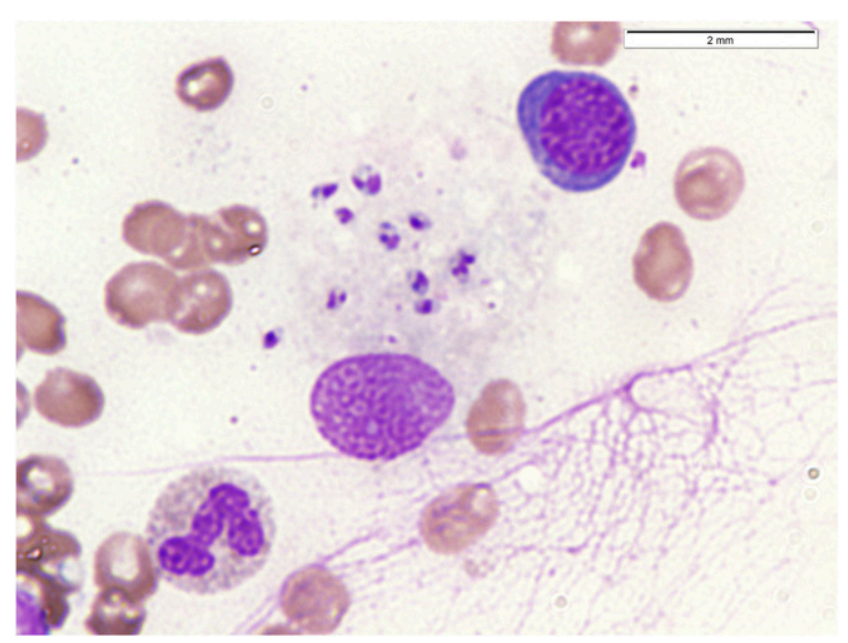

FIGURE 1. Giemsa-stained bone marrow smear showing intracellular amastigotes as pale-blue oval bodies, 2-5 $\mu \mathrm{m}$ in diameter, with a single violet-blue nucleus. The point-shaped kinetoplast is also evident. This figure appears in color at www.ajtmh.org.

(reference range: $6-17 \times 10^{3} / \mu \mathrm{L}$ ), and thrombocyte count of $90.0 \times 10^{3} / \mu \mathrm{L}$ (reference range: $140-400 \times 10^{3} / \mu \mathrm{L}$ ), mean corpuscular volume of 68.2 (reference range: $70-86 \mathrm{fL}$ ), mean cell hemoglobin of 21.4 (reference range: $23-31 \mathrm{pg}$ ), and mean corpuscular hemoglobin concentration of 31.4 (reference range: $30-36 \%)$. C-reactive protein was high, reaching 159 (0-10 mg/L). Liver enzymes (alanine transaminase and aspartate aminotransferase were normal. Kidney function tests (blood urea nitrogen and creatinine) were also normal. Serum electrolytes that included sodium, potassium, calcium, and magnesium were normal. Extracellular amastigotes were demonstrated in the Giemsa-stained bone marrow film, indicating a VL (Figure 1). The BLAST search of the isolated DNA sequence against leishmania sequences in the GenBank (www.ncbi.nlm.nih.gov) database revealed $L$. infantum as the causative agent. The isolated $L$. infantum sequence was deposited in GenBank under accession number MK311268. The patient was put on $2 \mathrm{~mL} /$ day intravenous Pentostam ${ }^{\mathrm{TM}}$ (GlaxoSmithKline, Brentford, UK) therapy (sodium stibogluconate) for 29 days, which is usually given at a rate of
0.1-0.2 $\mathrm{mL}\left(10-20 \mathrm{mg} \mathrm{Sb}{ }^{5+}\right) / \mathrm{kg}$ for a maximum of $8.5 \mathrm{~mL}$ Pentostam for 20 days. Imipenem, a potent broad-spectrum carbapenem, was given intravenously for 6 days. After 20 days of hospitalization, the hemoglobin level increased to $12.2 \mathrm{~g} /$ $\mathrm{dL}$, erythrocytes 5.01 , and leucocytes 6.1 . However, platelet count remained low, whereas CRP (114 mg/L) and ESR $(40 \mathrm{~mm})$ were high. The erythrocyte sedimentation rate is falsely elevated because of severe anemia. Clinical chemistry profiles that included kidneys, heart, and liver function tests and serum electrolytes were performed regularly during the Pentostam therapy (Table 1).

After completion of treatment, the hemoglobin level increased to $13.5 \mathrm{~g} / \mathrm{dL}$, thrombocytes to $150,000 / \mu \mathrm{L}$, and liver size reverted to normal. Further investigation to pinpoint the source of infection in the village was conducted. The investigation targeted the components of the life cycle, namely, the sandfly vector and the reservoir/host dogs. Seventeen sandflies were collected from the indoor corners of the patient's house using a sandfly aspirator. At the same time, serum was collected from 39 dogs. All sand flies were females except two males, with 16 of them being Phlebotomus papatasi, the vector for Leishmania major. One belonged to Sergentomyia dentata. None of the sand flies contained $L$. infantum parasite DNA in their gut. Of the 39 dog sera, six $(15.4 \%)$ were positive for antileishmanial antibodies. Three of these seropositive dogs showed at least one symptom compatible with VL, whereas the other three were asymptomatic. Seropositive dogs were quelled according to protocol.

\section{DISCUSSION}

This autochthonous HVL case report confirmed, by DNA sequencing, $L$. infantum as the cause of HVL in Palestine (GenBank: MK311268). Human visceral leishmaniasis has declined from 18 cases in 1996 to three cases in 2017 at an annual incidence rate ranging from 0.6 to 0.02 cases per 100,000 within the same period. ${ }^{13}$ The findings in this report are in agreement with previous studies on canine $\mathrm{VL}$ in the same area in which canine VL has been proven to be caused by $L$. infantum parasites at a seropositivity rate of $17 \% .^{9,12,22,23}$ The distribution of the cases was mainly in the rural areas of the western side of the West Bank and affecting

TABLE 1

Clinical chemistry profiles for the visceral leishmaniasis patient during Pentostam therapy

\begin{tabular}{lccc}
\hline \multicolumn{1}{c}{ Test } & Patient range & Reference value & Flag \\
\hline Alanine transaminase & $10-21.3$ & $0-33 \mathrm{U} / \mathrm{L}$ & $\mathrm{Normal}$ \\
Aspartate aminotransferase & $22.8-31.4$ & $0-37 \mathrm{U} / \mathrm{L}$ & $\mathrm{Normal}$ \\
Lactate dehydrogenase & $303-380$ & $180-430 \mathrm{U} / \mathrm{L}$ & $\mathrm{Normal}$ \\
Creatine kinase, total & $20-24$ & $0-170 \mathrm{U} / \mathrm{L}$ & $\mathrm{Normal}$ \\
Creatinine & $0.17-0.63$ & $0.5-0.9 \mathrm{mg} / \mathrm{dL}$ & $\mathrm{Normal}$ \\
Blood urea nitrogen & $5.3-8$ & $5-18 \mathrm{mg} / \mathrm{dL}$ & $\mathrm{Normal}$ \\
Uric acid & 3.1 & $1.7-5.8 \mathrm{mg} / \mathrm{dL}$ & $\mathrm{Normal}$ \\
High-sensitive C-reactive protein & 114 & $0-5 \mathrm{~g} / \mathrm{L}$ & Increased \\
Erythrocyte sedimentation rate & $40-159$ & $0-10 \mathrm{~mm}$ & Increased \\
Total iron binding capacity & $209-228$ & $250-425 \mu \mathrm{g} / \mathrm{dL}$ & Decreased \\
Ferritin & 979 & $4.63-204 \mathrm{ng} / \mathrm{mL}$ & Increased \\
Iron, total & 13.7 & $37-145 \mu \mathrm{d} / \mathrm{dL}$ & $\mathrm{Decreased}$ \\
Calcium & 9.3 & $9-11 \mathrm{mg} / \mathrm{dL}$ & $\mathrm{Normal}$ \\
Sodium & 136 & $136-145 \mathrm{mEq} / \mathrm{L}$ & $\mathrm{Normal}$ \\
Magnesium & 2.01 & $1.6-2.6 \mathrm{mg} / \mathrm{dL}$ & $\mathrm{Normal}$ \\
Potassium & 4.5 & $3.5-5.1 \mathrm{mEq} / \mathrm{L}$ & $\mathrm{Normal}$ \\
Glucose, random & 123 & $74-110 \mathrm{mg} / \mathrm{dL}$ & Increased \\
\hline
\end{tabular}


children in particular. The family including the patient has no previous history with HIV. The rural area is leading a noticeable agricultural activity with domestic and stray dogs around. This case report instantiates the need to consider HVL in cases of prolonged fever of unknown origin or hepatomegaly. Early detection and timely treatment of HVL is paramount because of the high mortality rate of untreated cases. Pentostam therapy is effective in treating HVL cases in Palestine without any signs of resistance. Sandfly vectors and reservoir dogs should be considered for the control of HVL parallel to health awareness campaigns.

Received February 12, 2020. Accepted for publication June 19, 2020.

Published online July 27, 2020.

Acknowledgment: The American Society of Tropical Medicine and Hygiene (ASTMH) assisted with publication expenses.

Authors' addresses: Ahmed Al-Jawabreh and Suheir Ereqat, Faculty of Medicine, Al-Quds University, Jerusalem, Palestine, E-mails: ahmed.aljawabreh000@gmail.com and sereqat@staff.alquds.edu. Kamal Dumaidi, Arab American University, Jenin, Palestine, E-mail: kamal.dumaidi@aaup.edu. Abdelmajeed Nasereddin and Hanan AlJawabreh, Leishmaniases Research Unit, Jericho, Palestine, E-mails: abedn@ekmd.huji.ac.il and al.jawabreh@gmail.com. Samer Sawalha, Ministry of Health, Ramallah, Palestine, E-mail: ss_sawalha@yahoo. com. Amer Al-Jawabreh, Leishmaniases Research Unit, Jericho, Palestine, and Arab American University, Jenin, Palestine, E-mails: islahjr@yahoo.com or amer.aljawabreh@aaup.edu.

\section{REFERENCES}

1. Ready PD, 2010. Leishmaniasis emergence in Europe. Euro Surveill 15: 19505.

2. Gallego M, Pratlong F, Fisa R, Riera C, Rioux JA, Dedet JP, Portus $M, 2001$. The life-cycle of Leishmania infantum MON-77 in the Priorat (Catalonia, Spain) involves humans, dogs and sandflies; also literature review of distribution and hosts of $L$. infantum zymodemes in the Old World. Trans $R$ Soc Trop Med Hyg 95: 269-271.

3. Rassi Y, Javadian E, Nadim A, Rafizadeh S, Zahraii A, Azizi K, Mohebali M, 2009. Phlebotomus perfiliewi transcaucasicus, a vector of Leishmania infantum in northwestern Iran. $J$ Med Entomol 46: 1094-1098.

4. Alten B et al., 2016. Seasonal dynamics of phlebotomine sand fly species proven vectors of mediterranean leishmaniasis caused by Leishmania infantum. Plos Negl Trop Dis 10: e0004458.

5. Maroli M, Feliciangeli MD, Bichaud L, Charrel RN, Gradoni L, 2013. Phlebotomine sandflies and the spreading of leishmaniases and other diseases of public health concern. Med Vet Entomol 27: 123-147.

6. Léger N, Marchais R, Madulo-Leblond R, Pesson B, Kristensen A, Ferté H, Killick-Kendrick R, Killick-Kendrick M, 1991. Les phlébotomes impliqués dans la transmission des leishmanioses dans l'île de Gozo (Malte). Ann Parasitol Hum Comp 66: 33-41.

7. Ribeiro RR, Michalick MSM, da Silva ME, Dos Santos CCP, Frezard FJG, da Silva SM, 2018. Canine leishmaniasis: an overview of the current status and strategies for control. Biomed Res Int 2018: 3296893.

8. Moreno J, Alvar J, 2002. Canine leishmaniasis: epidemiological risk and the experimental model. Trends Parasitol 18: 399-405.

9. Hamarsheh O, Nasereddin A, Damaj S, Sawalha S, Al-Jawabreh H, Azmi K, Amro A, Ereqat S, Abdeen Z, Al-Jawabreh A, 2012. Serological and molecular survey of Leishmania parasites in apparently healthy dogs in the West Bank, Palestine. Parasit Vectors 5: 183.

10. Pace D, Williams TN, Grochowska A, Betts A, Attard-Montalto S, Boffa MJ, Vella C, 2011. Manifestations of paediatric Leishmania infantum infections in Malta. Travel Med Infect Dis 9: 37-46.

11. WHO, 2019. Visceral Leishmaniasis Fact Sheet. Available at: https://www.who.int/news-room/fact-sheets/detail/leishmaniasis. Accessed July 15, 2019.

12. Nasereddin A, Ereqat S, Azmi K, Baneth G, Jaffe CL, Abdeen Z, 2006. Serological survey with $P C R$ validation for canine visceral leishmaniasis in northern Palestine. J Parasitol 92: 178-183.

13. Palestinian Ministry of Health, 2019. Annual Health Reports, 1996-2018. Ramallah, Palestine: Ministry of Health.

14. Sawalha SS, Shtayeh MS, Khanfar HM, Warburg A, Abdeen ZA, 2003. Phlebotomine sand flies (Diptera: Psychodidae) of the Palestinian West Bank: potential vectors of leishmaniasis. J Med Entomol 40: 321-328.

15. Bain BJ, 2001. Bone marrow aspiration. J Clin Pathol 54: 657-663.

16. Garcia LS, 2009. Practical Guide to Diagnostic Medical Parasitology. Washington, DC: ASM Press.

17. el Tai NO, Osman OF, el Fari M, Presber W, Schonian G, 2000. Genetic heterogeneity of ribosomal internal transcribed spacer in clinical samples of Leishmania donovani spotted on filter paper as revealed by single-strand conformation polymorphisms and sequencing. Trans $R$ Soc Trop Med Hyg 94: 575-579.

18. Schonian G, Nasereddin A, Dinse N, Schweynoch C, Schallig HD, Presber W, Jaffe CL, 2003. PCR diagnosis and characterization of Leishmania in local and imported clinical samples. Diagn Microbiol Infect Dis 47: 349-358.

19. Al-Jawabreh A, Schnur LF, Nasereddin A, Schwenkenbecher JM, Abdeen Z, Barghuthy F, Khanfar H, Presber W, Schonian G, 2004. The recent emergence of Leishmania tropica in Jericho (A'riha) and its environs, a classical focus of $L$. major. Trop Med Int Health 9: 812-816.

20. Sabat AJ, van Zanten E, Akkerboom V, Wisselink G, van Slochteren K, de Boer RF, Hendrix R, Friedrich AW, Rossen JWA, Kooistra-Smid A, 2017. Targeted next-generation sequencing of the $16 \mathrm{~S}-23 \mathrm{~S}$ rRNA region for culture-independent bacterial identification-increased discrimination of closely related species. Sci Rep 7: 3434.

21. Abbasi I et al., 2018. Plant-feeding phlebotomine sand flies, vectors of leishmaniasis, prefer Cannabis sativa. Proc Natl Acad Sci U S A 115: 11790-11795.

22. Khaldoun A, Schnur LF, Nasereddin A, Pratlong F, Dedet J-P, Shaheen L, Yousef O, Greenblatt CL, 2005. Short communication: palestinian infantile visceral leishmaniasis caused by a genetic variant of Leishmania infantum belonging to a new zymodeme. Trop Med Int Health 10: 618-620.

23. Amro Azmi K, Schönian G, Nasereddin A, Alsharabati MB, Sawalha S, Hamarsheh O, Ereqat S, Abdeen Z, 2009. Epidemiology of paediatric visceral leishmaniasis in Hebron district, Palestine. Trans R Soc Trop Med Hyg 103: 731-736. 